\title{
Acute Toxicity Evaluation of Non-Innocent Oxidovanadium(V) Schiff Base Complex
}

\author{
Lidiane M. A. Lima $\left.^{1}{ }^{(}\right)$, Heide Murakami ${ }^{2}{ }^{\circledR}$, D. Jackson Gaebler ${ }^{2}$, Wagner E. Silva ${ }^{1}{ }^{\circledR}$, Mônica F. Belian ${ }^{1}$, \\ Eduardo C. Lira ${ }^{3, *(\mathbb{D})}$ and Debbie C. Crans ${ }^{2,4}$ (D) \\ 1 Departamento de Química, Universidade Federal Rural de Pernambuco, Recife-PE 52171-900, Brazil; \\ lidianelimaa@gmail.com (L.M.A.L.); wesdqr@gmail.com (W.E.S.); mfbelian@gmail.com (M.F.B.) \\ 2 Department of Chemistry, Colorado State University, Fort Collins, CO 80523, USA; \\ heideam@gmail.com (H.M.); jackson.Gaebler@rams.colostate.edu (D.J.G.); \\ debbie.crans@coloState.edu (D.C.C.) \\ 3 Centro de Biociências, Departamento de Fisiologia e Farmacologia, Universidade Federal de Pernambuco, \\ Recife-PE 50670-901, Brazil \\ 4 Cell and Molecular Biology Program, Colorado State University, Fort Collins, CO 80513, USA \\ * Correspondence: eduardo.clira2@ufpe.br; Tel./Fax: +55-(81)-996368873
}

Citation: Lima, L.M.A.; Murakami, H.; Gaebler, D.J.; Silva, W.E.; Belian, M.F.; Lira, E.C.; Crans, D.C. Acute Toxicity Evaluation of Non-Innocent Oxidovanadium(V) Schiff Base Complex. Inorganics 2021, 9, 42. https://doi.org/10.3390/ inorganics 9060042

Academic Editor: Isabel Correia

Received: 20 February 2021

Accepted: 13 May 2021

Published: 24 May 2021

Publisher's Note: MDPI stays neutral with regard to jurisdictional claims in published maps and institutional affiliations.

Copyright: (c) 2021 by the authors. Licensee MDPI, Basel, Switzerland. This article is an open access article distributed under the terms and conditions of the Creative Commons Attribution (CC BY) license (https:/ / creativecommons.org/licenses/by/ $4.0 /)$.

\begin{abstract}
The vanadium(V) complexes have been investigated as potential anticancer agents which makes it essential to evaluate their toxicity for safe use in the clinic. The large-scale synthesis and the acute oral toxicity in mice of the oxidovanadium(V) Schiff base catecholate complex, abbreviated as [VO(HSHED)dtb] containing a redox-active ligand with tridentate Schiff base (HSHED = N-(salicylide neaminato)-N'-(2-hydroxyethyl)-1,2-ethylenediamine) and $\mathrm{dtb}=3,5$-di-(t-butyl)catechol ligands were carried out. The body weight, food consumption, water intake as well biomarkers of liver and kidney toxicity of the [VO(HSHED)dtb] were compared to the precursors, sodium orthovanadate, and free ligand. The 10-fold scale-up synthesis of the oxidovanadium $(\mathrm{V})$ complex resulting in the preparation of material in improved yield leading to $2-3 \mathrm{~g}$ (79\%) material suitable for investigating the toxicity of vanadium complex. No evidence of toxicity was observed in animals when acutely exposed to a single dose of $300 \mathrm{mg} / \mathrm{kg}$ for 14 days. The toxicological results obtained with biochemical and hematological analyses did not show significant changes in kidney and liver parameters when compared with reference values. The low oral acute toxicity of the [VO(HSHED)dtb] is attributed to redox chemistry taking place under biological conditions combined with the hydrolytic stability of the oxidovanadium $(\mathrm{V})$ complex. These results document the design of oxidovanadium(V) complexes that have low toxicity but still are antioxidant and anticancer agents.
\end{abstract}

Keywords: oxidovanadium(V); vanadium Schiff base coordination complex; low acute toxicity

\section{Introduction}

A wide range of vanadium(IV) and (V) coordination complexes and salts display desirable biological effects such as antidiabetic and anticancer agents [1-19]. Vanadium coordination complexes such as bis(maltolato)oxidovanadium(IV) (BMOV) [5,9] and bis(allixinato)oxidovanadium(IV) ([VO(alx) 2$]$ ) (Figure 1) [20] have been found to result in glucose-lowering levels in streptozotocin (STZ)-induced rats [21-26]. Furthermore, vanadium Schiff base complexes such as dioxidovanadium(V)dipicolinate $\left(\left[\mathrm{VO}_{2} \operatorname{dip}\right.\right.$ ic $\left.]^{-}\right)[18,27,28]$ and $\mathrm{V}(\mathrm{V})$-catecholate substituted complexes as [VO(HSHED)dtb] [19] and [VO(naph-L-Pheol-im)(8HQ)] [1] have demonstrated anticancer properties against human ovarian, prostate and brain cells as well as enhancing the effects of oncolytic viruses (Figure 1). 


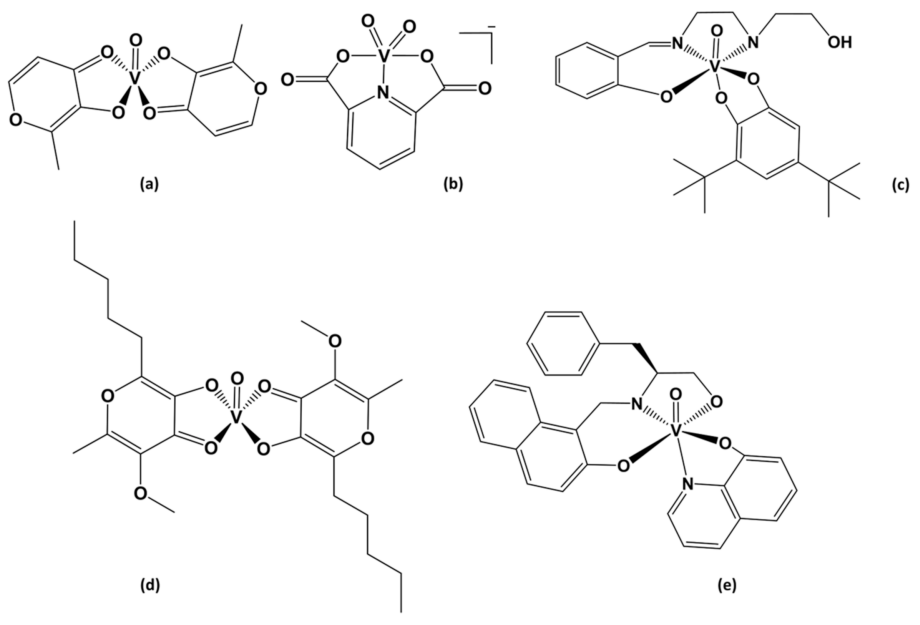

Figure 1. Structures of vanadium complexes with antidiabetic and/or anticancer properties, (a) bis(maltolato)oxidovanadium(IV) [BMOV], (b) dioxidovanadium(V)dipicolinate $\left[\mathrm{VO}_{2}\left(\right.\right.$ dipic) ${ }^{-}$, (c) $\mathrm{V}(\mathrm{V})$-catecholate substituted [VO(HSHED)dtb] (Hshed = N-(salicylideneaminato)-N'-(2-hydr oxyethyl)-1,2-ethylenediamine and $\mathrm{dtb}=3,5-\mathrm{di}(\mathrm{t}$-butyl)catechol), (d) bis(allixinato) oxidovana$\operatorname{dium}(\mathrm{IV})\left[\mathrm{VO}(\mathrm{alx})_{2}\right]$, and (e) V(V)-Schiff base substituted [VO(naph-L-Pheol-im)(8HQ)] (L-pheol-im = L-phenylalaninol, $8 \mathrm{HQ}=$ hydroxyquinoline).

Due to the prospective application of various compounds as therapeutic agents, significant effort has been directed toward demonstrating that such compounds have no toxic effects in vivo and in vitro [29-31]. In the case of vanadium compounds, few studies have been carried out to determine the toxicity of the coordination complexes [32], although literature reports exist for vanadium salts and simple vanadium oxides [32-34]. It has been known that an excess of vanadate induces toxic effects in cells by oxidative stress increasing [35-37]. In vivo and in vitro studies show that high levels of reactive oxygen species are often implicated in vanadium deleterious effects [38-41]. However, the ability of V-complexes to inhibit protein phosphatases enhances their potential application as a therapeutic agent and has been an area of extensive research [42].

The presence of catechol-moieties is an established feature of leading anticancer agents used in the clinic including doxorubicin, daunorubicin, and mitomycin C (quinone-based compounds) [43-45]. Furthermore, the Schiff base vanadium complexes containing catecholates display a particularly interesting redox-chemistry in cell environments and have been investigated due to antidiabetic [46,47] and anticancer properties [19,48-53], however, there is no study with a focus on their toxicity. Thus, the evaluation of the toxicity of vanadium Schiff base catecholate complexes in vivo and in vitro is fundamentally important for potential medicinal applications [54].

In this manuscript, the focus is to evaluate the toxicity of the vanadium Schiff base dit-butyl substituted catecholate complex-[VO(HSHED)dtb] — compared with the vanadate and the free catecholate ligand. The toxicological analysis was performed as recommended by the OECD (Organization for Economic Cooperation and Development) 423 guidelines characterizing the acute toxicity in mice.

\section{Results}

\subsection{Synthesis of [VO(HSHED)dtb] Complex}

Considering that the amount of material to carry out in vivo animal studies was 100 times greater than the scale of the vanadium catecholate previously prepared, it was necessary to scale up the reactions to prepare the target compounds for the biological studies. Furthermore, considering that $\mathrm{V}(\mathrm{V})$-Schiff base vanadium complexes are noninnocent coordination complexes and thus redox-active, attempts to change the reaction scale was non-trivial. Impure side products were avoided maintaining the reaction under argon atmosphere and the solvent to reactant ratio was kept as that described in the 
originally reported reaction $[19,55,56]$. Increasing the literature reported milligrams starting material reactions by a factor of about 7-10 but keeping the reactant-solvent ratios (1:70) constant, gram-scale of the target compound was obtained in each run. The major change to the scaled-up reactions was increasing the reaction time from $3 \mathrm{~h}$ to $48 \mathrm{~h}$. This increased the amounts of products, from $200 \mathrm{mg}$ to $2 \mathrm{~g}$ for each reaction. Interestingly, despite the scale-up of the reactions, the yields increased to $79 \%$ from the first reported $40 \%$ [55]. The improved yield is due to the longer reaction times in addition to minimizing oxidation by keeping the reaction under argon. ${ }^{51} \mathrm{~V}$ NMR of the scaled-up reaction product was identical to the reported previously $[55,56]$.

\subsection{Stability of $[V O(H S H E D) d t b]$ Complex}

Studies were previously carried out with [VO(HSHED)dtb] and were found to remain stable for few hours in cell culture media so the compound could be taken up by cells $[19,56]$. Even though the compound has low water solubility, it was found to be readily absorbed into cells from cell culture studies [56].

Furthermore, a low concentration was observed in membrane model studies. Although upon extended periods of time (5-24 h) contact with water will result in complex hydrolysis. The compound hydrolyzes to form starting materials, vanadate, catechol, Schiff base ligand which then degrades into salicylaldehyde and amine as reported previously $[19,56]$. However, the [VO(HSHED)dtb] has a longer lifetime than other Schiff base catecholate vanadium complexes and remains intact for a few hours before hydrolysis in various aqueous environments.

The experimental design called for administration of [VO(HSHED)dtb] by oral gavage, the concerns with compound solubility are less. We point to the fact the hydrophobic nature of this compound would increase the absorption of the complex once it was administered. Furthermore, if the solutions are freshly prepared and used immediately the amount of hydrolysis is minimized. That is, this mode of administration would allow delivery of compounds with low water solubility and lower stability because compounds would be delivered directly to the stomach of the animal.

To determine how much of the [VO(HSHED)dtb] was intact during the treatment, the UV-Vis (Ultraviolet-visible spectroscopy) under the conditions the compound was administered for the toxicological studies were investigated. In Figure 2, is shown the UV-Vis spectra of [VO(HSHED)dtb] dissolved in 5\%,10\%, and 20\% Tween 80 compared to a spectrum where the compounds were dissolved in DMSO and added to an aqueous solution. We carried out these studies as a function of time ranging from $t=0$ (black curves) to $\mathrm{t}=24 \mathrm{~h}$ (turquoise curves) at three different Tween 80 concentrations. As observed in Figure 2 all samples were sufficiently stable for the short periods of time needed for the administration, and importantly the addition of Tween 80 did not reduce the stability of the compounds significantly. However, significant amounts of compound decomposed after $24 \mathrm{~h}$, particularly in the presence of the Tween 80 . We conclude that Tween 80 destabilizes [VO(HSHED)dtb] but that over $24 \mathrm{~h}$ of time the presence of Tween 80 facilitates the complete hydrolysis and more rapidly than the control aqueous solution. 

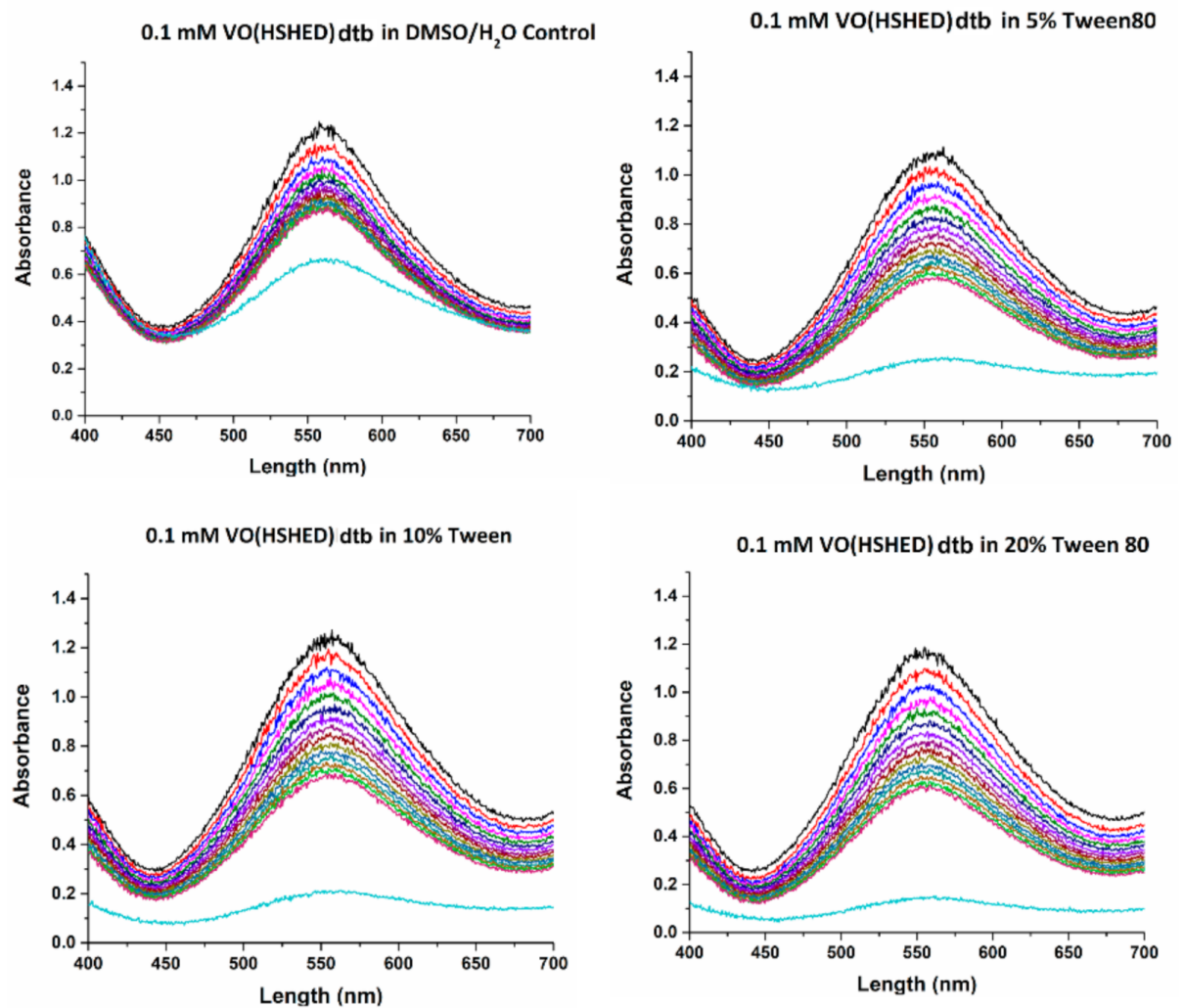

Figure 2. The UV-Vis spectra are shown of $0.1 \mathrm{mM}$ [VO(HSHED)dtb] in DMSO, $\mathrm{H}_{2} \mathrm{O}$, and in $5 \%$, $10 \%$, and $20 \%$ Tween 80 at various time increments, from $\mathrm{t}=0 \mathrm{~h}$ to $\mathrm{t}=24 \mathrm{~h}$.

Administration of compounds in animals is always subjected to the pharmacokinetic and ADME (Absorption, Distribution, Metabolism, and Excretion) as well as the pharmacodynamic, and as such it is of interest what forms of the compounds are present. However, since the compounds are rapidly distributed making concentrations low, and it is non-trivial to measure since this compound undergoes both hydrolytic and redox chemistry $[19,56]$, methods are being developed to measure such different forms $[57,58]$. However, at present it seems pertinent and more profitable for the determination of whether the compound is toxic, to measure the impact on toxicity markers. Such an approach is particularly beneficial if these parameters are compared to marker formation in animals treated with the potentially toxic hydrolysis products, vanadate, and catecholate.

\subsection{Acute Toxicity in Mice}

Neither animal mortality, severe toxicity nor detrimental side effects were observed during the entire 14 days experimental period in all groups, except for the very high concentration $(2000 \mathrm{mg} / \mathrm{kg})$ of [VO(HSHED)dtb]. At the high dose administration of vanadium(V) Schiff base complex resulted in the death of all animals during the first $24 \mathrm{~h}$, and as a result, it was not possible to collect the data on the 14th day. In contrast, no signs of toxicity were observed after the administration of [VO(HSHED) $\mathrm{dtb}$ ) in a single dose of 300 $\mathrm{mg} / \mathrm{kg}$, i.e., no-observed adverse-effect level (NOAEL). Neither behavior alterations like lethargy, sleep, tremors, salivation, convulsion, nor common side effects for V-compounds, such as diarrhea, were observed in all groups for 14 days [59].

The acute toxicity was performed using OECD 423 guideline. The OECD is an international organization that works to build better policies for better lives, and they have developed protocols for animal studies [60]. This guideline allows the characterization of substances according to the Globally Harmonized System (GHS) for the classification of chemicals that cause acute toxicity. The classification of the test substance is based on the determination of the mortality dose(s), when there are no effects observed this concentration 
will be the highest dose tested by gavage in a single dose. Thus, the compounds could be rated as categories 1 to 5 , from the most to least toxic, according to the $\mathrm{LD}_{50}$ (median lethal dose) values in $\mathrm{mg} / \mathrm{kg}$ b.w from each category [60]. [VO(HSHED)dtb] and 3,5di(t-butyl)catechol was found to be category 4 , with median lethal dose $\mathrm{LD}_{50}$ estimated to be between $300 \mathrm{mg} / \mathrm{kg}$ and $2000 \mathrm{mg} / \mathrm{kg}$ b.w. and orthovanadate is more toxic than both (category 3) with $\mathrm{LD}_{50}$ estimated to be between $50 \mathrm{mg} / \mathrm{kg}$ and $300 \mathrm{mg} / \mathrm{kg}$ b.w. Furthermore, the use of female Swiss mice was chosen in this study because literature surveys of conventional $\mathrm{LD}_{50}$ tests show that usually there is little difference in sensitivity between the sexes, but in these cases where differences are observed, females are generally slightly more sensitive [61].

\subsection{Clinical Observations}

The observations were made on the animals treated with the vanadium coordination complex, orthovanadate salt, the catechol ligand, and control group. Figure 3 shows that there is no statistical difference in body weight, food consumption, and water intake between the control treated with water and treated groups $(p>0.05)$ throughout 14 days and at the end of treatment (Table 1).

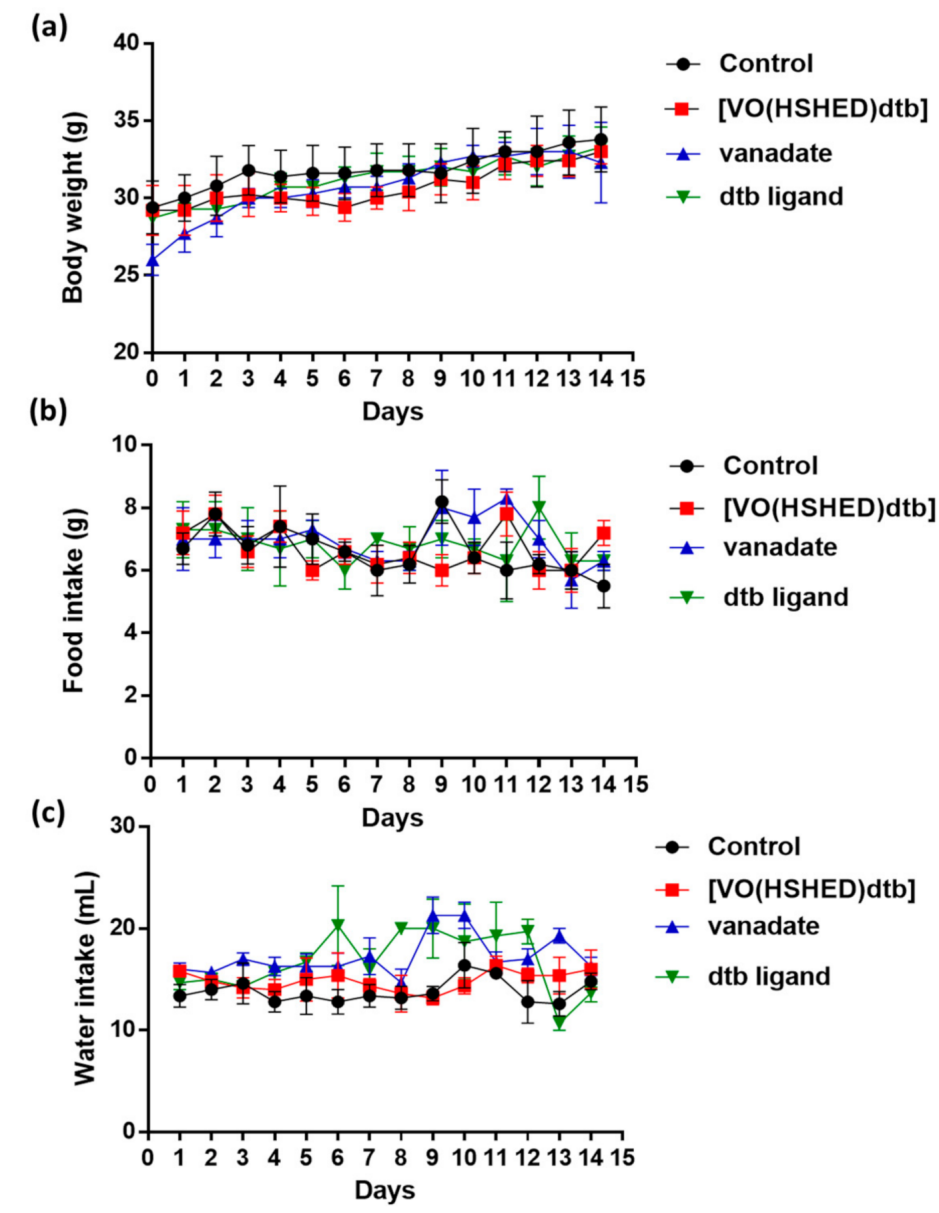

Figure 3. Effects on (a) body weight, (b) food intake, and (c) fluid intake throughout 14 days in mice administered acute levels of $300 \mathrm{mg} / \mathrm{kg}$ [VO(HSHED) dtb], $50 \mathrm{mg} / \mathrm{kg}$ orthovanadate and $300 \mathrm{mg} / \mathrm{kg}$ $\mathrm{dtb}$ ligand (3,5-di(t-butyl)catechol) groups by oral gavage. The data are presented as the mean $\pm \mathrm{SD}$ $(n=5)$. 
Table 1. Effects by acute oral administration of $300 \mathrm{mg} / \mathrm{kg}$ [VO(HSHED)dtb], $50 \mathrm{mg} / \mathrm{kg}$ orthovanadate, and $300 \mathrm{mg} / \mathrm{kg} \mathrm{dtb}$ ligand, in different mice groups with regards to body weight, weight gain, food intake, and water intake at day 14.

\begin{tabular}{ccccc}
\hline & \multicolumn{4}{c}{ Study Group } \\
\cline { 2 - 5 } Parameter & Control & [VO(HSHED)dtb] & Orthovanadate & 3,5-di(t-butyl)catechol \\
\hline Body weight $(\mathrm{g})$ & $31.8 \pm 1.8$ & $30.7 \pm 1.0$ & $30.8 \pm 0.9$ & $31.2 \pm 0.7$ \\
\hline Weight gain $(\mathrm{g})$ & $0.3 \pm 0.0$ & $0.3 \pm 0.1$ & $0.20 \pm .1$ & $0.2 \pm 0.1$ \\
\hline Food intake $(\mathrm{g} / 24 \mathrm{~h})$ & $6.8 \pm 0.3$ & $6.7 \pm 0.3$ & $7.0 \pm 0.1$ & $6.8 \pm 0.3$ \\
\hline Water intake $(\mathrm{mL} / 24 \mathrm{~h})$ & $13.8 \pm 0.8$ & $15.0 \pm 0.6$ & $17.3 \pm 0.5^{*}$ & $16.7 \pm 1.5$ \\
\hline
\end{tabular}

The data are presented as the mean $\pm \mathrm{SD}(n=5)$. Values are statistically significant at ${ }^{*} p<0.05$ compared to the control group.

Once the [VO(HSHED)dtb] was found to cause no changes in clinical parameters monitored at the $300 \mathrm{mg} / \mathrm{kg}$ level, the biochemical and hematological parameters were monitored to investigate further toxic effects of the compounds as shown in Tables 2 and 3. Furthermore, the macroscopic analysis did not show any changes in tissue weight such as liver, kidney, heart, spleen, and lung in animals treated with $300 \mathrm{mg} / \mathrm{kg}$ [VO(HSHED)dtb] for the 14 days as shown by the data summarized in Table 4 .

Table 2. Effects by acute oral administration of $300 \mathrm{mg} / \mathrm{kg}$ [VO(HSHED)dtb], $50 \mathrm{mg} / \mathrm{kg}$ orthovanadate, and $300 \mathrm{mg} / \mathrm{kg} \mathrm{dtb}$ ligand in different mice groups with regard to AST/ALT ratio, albumin, total proteins, globulin, and A/G ratio parameters at day 14.

\begin{tabular}{ccccc}
\hline & \multicolumn{4}{c}{ Study Group } \\
\cline { 2 - 5 } Biochemical Parameters & Control & [VO(HSHED)dtb] & Orthovanadate & 3,5-di(t-butyl)catechol \\
\hline AST/ALT ratio & $1.1 \pm 0.01$ & $0.9 \pm 0.02$ & $1.0 \pm 0.01$ & $1.1 \pm 0.01$ \\
\hline Albumin (g/dL) & $2.2 \pm 0.2$ & $2.1 \pm 0.1$ & $2.1 \pm 0.1$ & $2.1 \pm 0.1$ \\
\hline Total proteins (g/dL) & $5.7 \pm 0.4$ & $5.5 \pm 0.2$ & $6.5 \pm 0.6$ & $3.8 \pm 0.3$ \\
\hline Globulin (g/dL) & $3.5 \pm 0.3$ & $3.4 \pm 0.2$ & $4.3 \pm 0.5^{*}$ & 0.3 \\
\hline A/G ratio & $0.6 \pm 0.01$ & $0.6 \pm 0.01$ & $0.5 \pm 0.02$ & $0.6 \pm 0.02$ \\
\hline
\end{tabular}

The data are presented as the mean $\pm \mathrm{SD}(n=5)$. Values are statistically significant at ${ }^{*} p<0.05$ compared to the control group.

Table 3. Effects by acute oral administration of $300 \mathrm{mg} / \mathrm{kg}$ [VO(HSHED)dtb], $50 \mathrm{mg} / \mathrm{kg}$ orthovanadate, and $300 \mathrm{mg} / \mathrm{kg} \mathrm{dtb}$ ligand in different mice groups with regard to hematological parameters at day 14.

\begin{tabular}{|c|c|c|c|c|}
\hline \multirow[b]{2}{*}{ Hematological Parameters } & \multicolumn{4}{|c|}{ Study Group } \\
\hline & Control & [VO(HSHED)dtb] & Orthovanadate & 3,5-di(t-butyl)catechol \\
\hline Red blood cell $\left(10^{12} / \mathrm{L}\right)$ & $9.5 \pm 0.2$ & $9.3 \pm 0.2$ & $8.9 \pm 0.2$ & $9.7 \pm 0.3$ \\
\hline Mean corpuscular volume (Fl) & $57.6 \pm 0.2$ & $56.2 \pm 0.8$ & $57.0 \pm 0.6$ & $56.3 \pm 0.3$ \\
\hline Hemoglobin (g/dL) & $12.4 \pm 0.5$ & $12.5 \pm 0.1$ & $12.3 \pm 0.1$ & $13.4 \pm 0.2$ \\
\hline Mean corpuscular hemoglobin $(\rho g)$ & $13.5 \pm 0.5$ & $15.4 \pm 2.0$ & $13.7 \pm 0.3$ & $13.8 \pm 0.1$ \\
\hline $\begin{array}{l}\text { mean corpuscular hemoglobin } \\
\text { concentration }(\mathrm{g} / \mathrm{dL})\end{array}$ & $23.5 \pm 0.6$ & $23.9 \pm 0.2$ & $23.9 \pm 0.2$ & $24.4 \pm 0.1$ \\
\hline Hematocrit $(\%)$ & $52.6 \pm 0.9$ & $52.5 \pm 0.5$ & $51.6 \pm 0.8$ & $55.0 \pm 1.6$ \\
\hline White blood cell $\left(10^{9} / \mathrm{L}\right)$ & $12.6 \pm 1.3$ & $8.6 \pm 1.3 *$ & $12.7 \pm 1.9$ & $10.9 \pm 1.1$ \\
\hline Lymphocytes (\%) & $82.6 \pm 0.8$ & $81.8 \pm 0.9$ & $84.3 \pm 1.5$ & $83.2 \pm 1.3$ \\
\hline
\end{tabular}

\footnotetext{
The data are presented as the mean $\pm \mathrm{SD}(n=5)$. Values are statistically significant at ${ }^{*} p<0.05$ compared to the control group.
} 
Table 4. Effects by acute oral administration of $300 \mathrm{mg} / \mathrm{kg}$ [VO(HSHED) dtb], $50 \mathrm{mg} / \mathrm{kg}$ orthovanadate, and $300 \mathrm{mg} / \mathrm{kg} \mathrm{dtb}$ ligand in different mice groups with regard to the heart, kidney, liver, spleen, and lung weight at day 14.

\begin{tabular}{ccccc}
\hline & \multicolumn{4}{c}{ Study Group } \\
\cline { 2 - 5 } Organs (g/100 g b.w) & Control & [VO(HSHED)dtb] & Orthovanadate & 3,5-di(t-butyl)catechol \\
\hline Heart & $0.54 \pm 0.03$ & $0.53 \pm 0.02$ & $0.59 \pm 0.04$ & $0.60 \pm 0.07$ \\
\hline Kidney & $5.75 \pm 0.29$ & $6.23 \pm 0.38$ & $6.11 \pm 0.11$ & $5.50 \pm 0.54$ \\
\hline Liver & $1.36 \pm 0.10$ & $1.52 \pm 0.08$ & $1.70 \pm 0.20^{*}$ & $1.61 \pm 0.18$ \\
\hline Spleen & $0.48 \pm 0.05$ & $0.47 \pm 0.03$ & $0.66 \pm 0.06^{*}$ & $0.59 \pm 0.13$ \\
\hline Lung & $0.88 \pm 0.11$ & $0.79 \pm 0.03$ & $0.86 \pm 0.14$ & $0.75 \pm 0.15$ \\
\hline
\end{tabular}

The weight of body organs was measured in mice after 14 days of treatment. The data are presented as the mean \pm SD $(n=5)$. Values are statistically significant at ${ }^{*} p<0.05$ compared to the control group.

\subsection{Hematology and Biochemical Analysis}

Treatment with neither the $\mathrm{dtb}(3,5$-di(t-butyl)catechol) ligand nor orthovanadate administration caused any alteration in biochemical and hematology parameters, in contrast to treatment with [VO(HSHED)dtb] which slightly decreased the WBC (white blood cell) level $(p<0.05)$ as shown in Table 3.

The alanine and aspartate aminotransferases (abbreviated ALT and AST, respectively) are commonly used as a marker in the diagnosis of liver injury and disease [62]. High levels of serum ALT activity reflects damage to hepatocyte and is considered to be a highly sensitive and fairly specific preclinical and clinical biomarker of hepatotoxicity [63]. In the present study, there were no significant changes in hepatic enzymes as shown in Figure 4, suggesting that the [VO(HSHED)dtb] did not cause any damage to the hepatic functions. In addition, hepatic-cellular damage leads to a reduction in albumin accompanied by a relative increase in globulins, which decreases the $A / G$ ratio [64]. As shown in Table 2, no experimental significant difference between the control group and $300 \mathrm{mg} / \mathrm{kg}$ [VO(HSHED)dtb] $(p>0.05)$ at protein levels suggested the vanadium-catecholate complex did not cause hepatotoxicity in vivo.

As shown in Figure 4, no significant changes were observed in kidney biomarkers such as BUN (blood urea nitrogen) and creatinine which suggested that [VO(HSHED)dtb] did not cause nephrotoxicity [65]. However, the treatment with the free catechol ligand did increase significantly creatine levels $(p<0.05)$ documenting some toxicity is observed of the free ligand at $300 \mathrm{mg} / \mathrm{kg}$ single dose. These results provide evidence that the vanadium Schiff base catecholate complex does not exert toxicity in vivo up to therapeutic doses. 
(a)

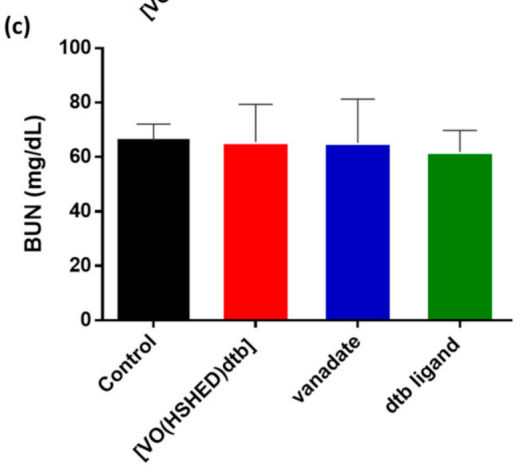

(b)

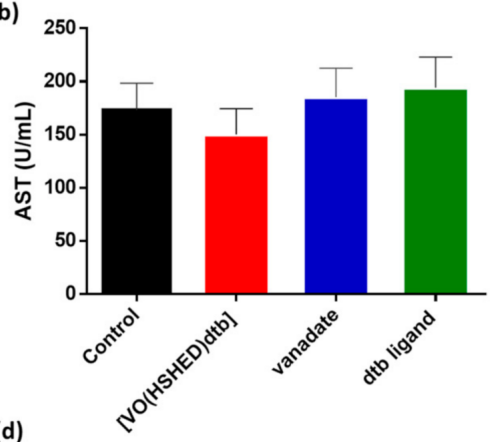

(d)

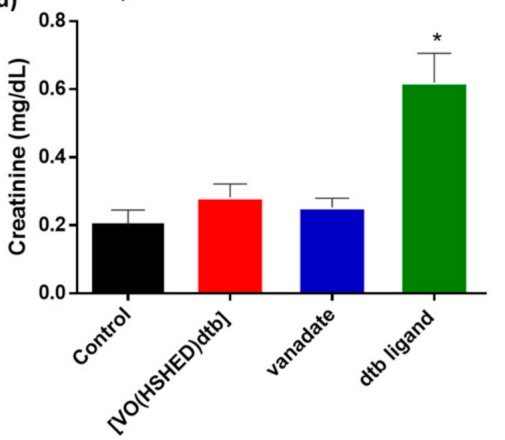

Figure 4. Effects by acute oral administration of $300 \mathrm{mg} / \mathrm{kg}$ [VO(HSHED)dtb], $50 \mathrm{mg} / \mathrm{kg}$ orthovanadate, and $300 \mathrm{mg} / \mathrm{kg}$ dtb ligand on mice groups with regard to biomarkers (a) ALT (Alanine aminotransferase), (b) AST (aspartate aminotransferase), (c) BUN (blood urea nitrogen), and (d) plasmatic creatinine levels on day 14. The data are presented as the mean $\pm S D(n=5)$. Values are statistically significant at $* p<0.05$ compared to the control group.

\section{Discussion}

The evaluation of the toxic effects of an oxidovanadium(V) Schiff base complex was carried out as a result of the recently discovered anticancer effects of this complex. This complex has anticancer activity against prostate, brain, and breast cancer cells [19,56], however, no previous toxicity studies of [VO(HSHED)dtb] in vivo have been reported. Previous toxicity studies were mainly carried out with simple salts and oxides, including metavanadate and orthovanadate, vanadyl sulfate, and vanadium pentoxide $[32,66,67]$. A few coordination complexes have also been investigated, and those include vanadium dipicolinate complexes $[28,68]$. This [VO(HSHED)dtb] complex was chosen because it is a non-innocent vanadium complex and thus can undergo redox chemistry both at the ligand and the metal site. This chemical reactivity is thus fundamentally different from the vanadium coordination compounds and salts that have previously been subjected to toxicity studies. Furthermore, the [VO(HSHED)dtb] compound deviates from these previous compounds in that it is more hydrolytically stable, and that results in it being significantly more readily taken up by cells. Finally, it was recently reported with anticancer properties that exceeded cisplatin [19].

In order to generate enough materials for toxicological studies, the preparation of the redox-active target compound was scaled up to a $2 \mathrm{~g}$ scale. The preparation of the compound was done without loss in yields. This was accomplished by keeping the reaction under argon, keeping the same substrate to solvent ratio (1:70) but increasing the reaction time. This approach saved much time in preparation of the 20-plus gram pure vanadium complex needed for the animal studies and suggests that although these compounds are not trivial to prepare there is potential for scale-up.

The toxicity of vanadium(IV) and (V) compounds with antidiabetic effects have been evaluated after acute parenteral administration but the effects are less compared to oral administration [69]. This is presumably because the compound is poorly absorbed by the gastrointestinal tract $[9,69]$. Nevertheless, attempts have been made to develop vanadium derivatives with biological effects and low toxicity like the coordination complex 
[bis(maltolato)oxidovanadium(IV)] (BMOV) [5,70]. This complex has high lipophilicity and was selected for clinical trials where it demonstrated glucose-lowering effects in animals and humans [5]. Similarly, as reported previously, the hydrophobic nature of this [VO(HSHED)dtb] would enhance the absorption of the complex and exert its anticarcinogenic effects [56].

Acute toxicity evaluation of [VO(HSHED)dtb] using a dose of $300 \mathrm{mg} / \mathrm{kg}$ did not induce mortality or symptoms of severe toxicity throughout the period of the experiment. Administration of oxidovanadium(V) Schiff base complex did not affect hematological indices, hepatic, and renal biomarkers levels. Furthermore, the most common side-effects of vanadium treatment, such as weight loss and diarrhea [59], were not observed after acute exposure to a dosage of $300 \mathrm{mg} / \mathrm{kg}$ [VO(HSHED)dtb] for 14 days.

Vanadium compounds are known to often convert to other species upon administration in biological environments [71]. The toxicity of the [VO(HSHED)dtb] should be determined and compared to the effects of its components, i.e., free ligand catechol, Schiff base, and vanadate before applications as a therapeutic compound [31,72-74]. The hydrolysis of the complex and the Schiff base generates the salicylaldehyde and the amine [19,56]. Since previous works have reported that simple aldehyde and amine-based compounds are safe and used for designing new drugs [75,76], accordingly, to investigate the most toxic component of the ligands we focused on catechols and designed an experiment investigating the toxicity of the catechol.

Although the parent catechol is known to show some toxicity, the 3,5-di(t-butyl)catechol is much less toxic with an $\mathrm{LD}_{50}$ value in mice of $1.040 \mathrm{~g} / \mathrm{kg}$ b.w. by OG (oral gavage) [77]. However, our results showed a slight increase of creatinine levels in animals treated with 3,5-di(t-butyl) catechol suggesting nephrotoxicity. Thus, both [VO(HSHED)dtb] and 3,5-di(t-butyl)catechol were rated at the same toxicity level according to the Globally Harmonized System (GHS) with $\mathrm{LD}_{50}$ values between 300 and $2000 \mathrm{mg} / \mathrm{kg}$.

The sodium orthovanadate salt has been reported to cause insulin-mimetic activity $[9,10]$, reduction in glucose levels in STZ-diabetic animals $[9,10]$ and be potent phosphatase inhibitors $[2,3]$, and previous toxic studies showed $\mathrm{LD}_{50}$ values in rats of 36.3 $\mathrm{mg} / \mathrm{kg}$ and $330 \mathrm{mg} / \mathrm{kg}$ [74]. Similar experiments with $\mathrm{NaVO}_{3}$ showed $\mathrm{LD}_{50}$ values in mice of $74.6 \mathrm{mg} / \mathrm{kg}$ and $35.9 \mathrm{mg} / \mathrm{kg}$ for oral and intraperitoneal (i.p) administration, respectively $[32,34,78]$. The toxicity of the [VO(HSHED)dtb] was found to be lower than vanadate. This result confirmed some previous reports that have shown the vanadium will be less toxic when coordinated to a ligand [5-8,79]. However, other complexes show similar effects between the vanadium coordination complex and salt which is explained the vanadium compound readily hydrolyze under physiological conditions [71].

Attributing the biological effects to coordination complexes is less trivial than simple organic compounds, because depending on the metal complex and the conditions such complexes may undergo ligand exchange, hydrolysis, or formation of oxidation products [80]. Therefore, it is important that the stability of the compounds under investigation be determined under the conditions of the biological system [71,80-83]. In this study, the stability of the [VO(HSHED)dtb] in the solutions used for oral gavage treatments was characterized. Since [VO(HSHED)dtb] has limited solubility aqueous solution and to be able to solubilize enough for oral gavage administration, $10 \%$ Tween 80 was used. Accordingly, we measured out the stability of [VO(HSHED)dtb] in 5\%, 10\%, and $20 \%$ Tween, and we found that the Tween barely affected the stability of [VO(HSHED)dtb]. The toxicity results we obtained showed that the [VO(HSHED)dtb] was less toxic, and this is consistent with the interpretation that the compound was intact for some time after administration.

Vanadium compounds undergo redox chemistry under physiological conditions, can act as a strong pro-oxidant, and interact synergistically with other oxidants enhancing oxidative stress $[84,85]$. These findings are consistent with redox chemistry taking place under biological conditions and may impact the low toxicity properties of the [VO(HSHED)dtb]. These results are very encouraging because they demonstrate that low toxicity of a vanadium complex is possible and importantly lower toxicity than the salt $\left(\mathrm{H}_{2} \mathrm{VO}_{4}^{-}\right)$and hence 
lend support for future potential applications on cancer therapy. These findings suggest that it will be possible to design vanadium complexes that have even lower toxicity even when containing redox-active components.

\section{Material and Methods}

\subsection{Reagents and Chemical Analysis}

Catechol, 3,5-di(t-butyl)catechol, salicylaldehyde, N-(2-hydroxyethyl) ethylenediamine, vanadyl sulfate were purchased from Sigma Aldrich. Chemicals were used without purification. HPLC (high performance liquid chromatography) grade solvents were used for the synthesis and characterization of the oxidovanadium(V) complex. The compounds were characterized in the Colorado State Central Instrumentation Facility. Nuclear Magnetic Resonance (NMR) measurements were performed using a Bruker spectrometer at 78.9 $\mathrm{MHz}$ for ${ }^{51} \mathrm{~V}$ and $400.13 \mathrm{MHz}$ for ${ }^{1} \mathrm{H}$, using 4096 scans and a window from -53 to -1043 ppm as reported previously [86-88]. $\mathrm{V}$ chemical shifts were measured in parts per million from $\mathrm{VOCl}_{3}$ as external standard at $0.00 \mathrm{ppm}$ with upfield shifts considered negative.

\subsection{Synthesis of $\left[\mathrm{VO}_{2}(\mathrm{HSHED})\right]$ Complex}

The precursor $\left[\mathrm{VO}_{2}(\mathrm{HSHED})\right]$ complex was synthesized using a condensation reaction between salicylaldehyde and $\mathrm{N}$-(2-hydroxyethyl)ethylenediamine followed by a coupling reaction to vanadyl sulfate using previously reported methods $[89,90]$. The NMR spectra have shown the complex to have ${ }^{51} \mathrm{~V}$ NMR chemical shifts consistent with the literature (-529 ppm vs. $\left.\mathrm{VOCl}_{3}\right)$ [89].

\subsection{Synthesis of $[V O(H S H E D) d t b]$ Complex}

To synthesize [VO(HSHED)dtb] complex, the 3,5-di(t-butyl)catechol (1.11 g, 5.00 $\mathrm{mmol}$ ) was added to a solution of [ $\left.\mathrm{VO}_{2}(\mathrm{HSHED})\right](1.45 \mathrm{~g}, 5.00 \mathrm{mmol})$ and stirred in 350 $\mathrm{mL}$ of acetone for $48 \mathrm{~h}$ under an argon atmosphere (Scheme 1) [89,90]. A dark purple solution formed after $10 \mathrm{~min}$. After $48 \mathrm{~h}$, the solution was concentrated to dryness, and then the solution was vacuum filtered. A minimal amount of acetone $(27 \mathrm{~mL})$ was used to dissolve the crude product, followed by the addition of $300 \mathrm{~mL}$ of hexane. The solution was left to precipitate overnight at $-20^{\circ} \mathrm{C}$. The precipitate was filtered, washed with cold hexane $(75 \mathrm{~mL})$, and dried on a pump for 4 days. Yield $1.90 \mathrm{~g}(79 \%)$. The solid has similar characteristics as reported [VO(HSHED)dtb] [19,89,91].
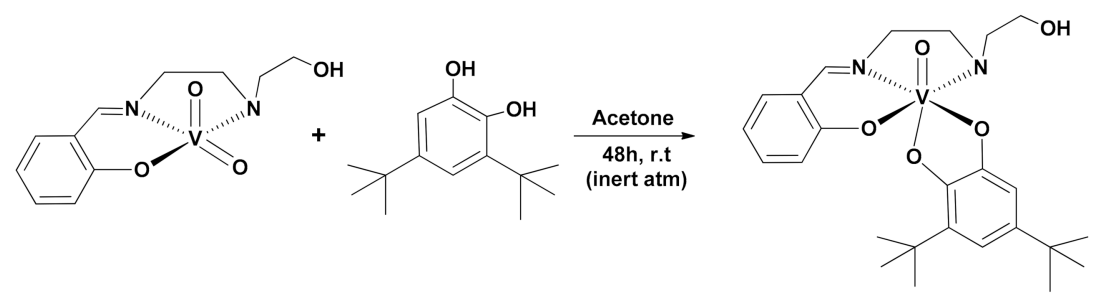

Scheme 1. Synthesis of [VO(HSHED)dtb] using precursor $\left[\mathrm{VO}_{2}(\mathrm{HSHED})\right]$ complex and 3,5-di(tbutyl) catechol.

\subsection{Stability of [VO(HSHED)dtb] Complex}

The stability of the [VO(HSHED)dtb] was measured using UV-Vis spectroscopy. [VO(HSHED)dtb] was dissolved in DMSO and added to an aqueous solution at the final concentration of $0.1 \mathrm{mM}$. The UV-Vis spectra were recorded at $\mathrm{t}=0 \mathrm{~h}$, and every $15 \mathrm{~s}$ following, and then again at $24 \mathrm{~h}$. Corresponding experiments were done with [VO(HSHED)dtb] dissolved in $5 \%, 10 \%$ and $20 \%$ Tween 80 to a final concentration of $0.1 \mathrm{mM}$. 


\subsection{Animals}

The protocols for these experiments were approved by the Animal Ethics Committee of the Universidade Federal de Pernambuco (process number \#004-2019) and conducted in accordance with the Ethical Principles in Animal Research. Twenty-five female Swiss mice ( $30 \pm 5 \mathrm{~g}$ ) were obtained from the Laboratory of the immunopathology of Keizo Asami (LIKA) at Universidade Federal de Pernambuco (UFPE) and the animal experiments were performed at the Laboratory of Neuroendocrinology and Metabolism at UFPE. The mice were housed in individual cages with a 1-12 light-dark cycle, $22 \pm 3{ }^{\circ} \mathrm{C}$, and were given free access to water and conventional lab chow diet ad libitum (Purina, Labina ${ }^{\circledR}$, Ribeirão Preto, Brazil) during the study period. All experiments were performed between 8:00 and 10:00 am.

\subsection{Acute Toxicity in Mice}

Acute oral toxicity effect of [VO(HSHED)dtb] was performed in accordance with the Organization for Economic Cooperation and Development (OECD) [60]. After 5 days of acclimatization in individual cages, non-pregnant and nulliparous female mice fasted overnight before the administration of compounds. The [VO(HSHED)dtb] was administered by gavage in mice at a single dose using animal feeding needles $(100 \mu \mathrm{L} / 100 \mathrm{~g} \mathrm{b.w})$. The [VO(HSHED)dtb] was dissolved in warm water $\left(50^{\circ} \mathrm{C}\right)$ with $10 \mu \mathrm{L}$ of $10 \%$ the surfactant Tween $80(\mathrm{v} / \mathrm{v})$ because of its poor solubility in water. Animals were randomly divided into 5 groups with 5 animals each: (a) negative control group which received only vehicle (distilled water), (b) group treated with low dose $300 \mathrm{mg} / \mathrm{kg}$ of [VO(HSHED)dtb], (c) group treated with high dose $2000 \mathrm{mg} / \mathrm{kg}$ of [VO(HSHED)dtb], (d) positive control group treated with $50 \mathrm{mg} / \mathrm{kg}$ of sodium orthovanadate, and (e) free ligand group treated with $300 \mathrm{mg} / \mathrm{kg}$ of 3,5-di(t-butyl)catechol.

Since there is no toxicological information about [VO(HSHED)dtb], in accordance with OECD 423 [60], [VO(HSHED)dtb] was evaluated at 2 doses and vanadate and free ligand groups were used in single dose because acute toxicity tests have been previously described in the literature [74,77]. After the administration period, animals were observed for mortality and clinical symptoms of toxicity daily for 14 days. The symptoms of toxicity analyzed were alterations on skin and eyes, mucous membrane toxic effects and behavior patterns, lethargy, sleep, diarrhea, tremors, salivation, convulsion, coma, motor activity, hypo-activity, abdominal rigidity, breathing difficulty, cyanosis, and death following the Hippocratic screening protocol. The consumption of water and feed, as well as the body weight of each animal, were recorded daily. In addition, animals were daily observed for general health conditions and clinical evidence of toxicity [92]. On the 14th day of experiment, fasting mice were anesthetized using ketamine (90\% b.w) and xilazin $(10 \%$ b.w), and the blood was drawn from the retro-orbital route with or without heparin for hematological and serum biochemical analysis, respectively. The following organs were removed, cleaned, weighed on an analytical scale, and macroscopically analyzed: liver, kidney, spleen, heart, and lung [93].

\subsection{Biochemical Analysis: Determination of Serum Biomarkers for Liver and Kidney Functions}

The blood samples on the 14th day were collected in dry tubes, were centrifuged (3000 $\mathrm{rpm}, 15 \mathrm{~min}$ ) and the obtained serums were analyzed for liver and kidney functions by colorimetric assay using commercial kits (Lab Test Diagnostic SA, Santa Lagoa, Brazil). Optical densities were measured by spectrophotometry (Varioskan TM Lux multimode microplate reader, Thermo Scientific ${ }^{\circledR}$, Waltham, MA, USA) at wavelengths specific for each biochemical parameter described on datasheets [93]. Baseline measurements were obtained by comparing the optical densities of the samples with the respective standards, available in the kits. Biochemical analysis was performed for determining the following biomarkers parameters: alanine (ALT) and aspartate aminotransferase (AST), total protein (TP), albumin (ALB), AST / ALT and albumin/globulin ratio (A/G), blood urea nitrogen (BUN), and creatinine (CRE). Globulin was obtained from the difference between total 
protein and albumin [94]. Data were expressed by U/mL (AST and ALT) and $\mathrm{mg} / \mathrm{dL}$ for the others.

\subsection{Hematology Analysis}

Hematological parameters included red blood cells (RBC), mean corpuscular volume (MCV), hemoglobin $(\mathrm{Hb})$, mean corpuscular hemoglobin $(\mathrm{MCH})$, mean corpuscular hemoglobin concentration (MCHC), hematocrit (HCT), white blood cells (WBC), lymphocytes (LYM) were performed using a multiparameter hematology analyzer (The Sysmex ${ }^{\circledR}$ XE-2100D, Sysmex ${ }^{\circledR}$, Curitiba, Brazil) designed for hematology testing samples with ethylenediaminetetraacetic acid (EDTA).

\subsection{Statistical Analysis}

In vivo data was expressed as mean \pm standard deviation (SD). The one-way analysis of variance (ANOVA) was employed to analyze the data between treated groups and their respective control groups followed. Tukey's Multiple Comparison Test was used to analyze the statistical comparisons. The $p$ values less than 0.05 were considered statistically significant among the groups. Graph Pad Prism ${ }^{\circledR}$ (GraphPad Software, San Diego, CA, USA), version 5.0 software was used for all statistical analysis.

\section{Conclusions}

In summary, the administration of [VO(HSHED)dtb] complex in mice did not show any signs of toxicity up to a dose of $300 \mathrm{mg} / \mathrm{kg}$. The complex was found to be less toxic than orthovanadate salt consistent with the compound being at least partially intact during the administration. The hematology, liver, and kidney biomarkers parameters demonstrate that the vanadium Schiff base complex exerts neither hepatotoxicity nor nephrotoxicity in mice. Although this compound contains both vanadium and a catechol which individually are known to be redox-active, and exert some toxicity, administration of this complex was tolerated at a low level $\left(0.6 \mathrm{~mol} \mathrm{~L}^{-1}, 300 \mathrm{mg} / \mathrm{kg}\right)$. It was found to be toxic at a high level $\left(4.0 \mathrm{~mol} \mathrm{~L}^{-1}, 2000 \mathrm{mg} / \mathrm{kg}\right)$ giving it an estimated $\mathrm{LD}_{50}$ between 300 and $2000 \mathrm{mg} / \mathrm{kg}$, the latter being significantly higher than the usual therapeutic doses.

The low toxicity is attributed to the redox properties obtained when combining the redox-active ligand 3,5-di(tert-butyl)catechol with the hydrolytic stability of the [VO(HSH ED)dtb], which prevent the formation of the vanadate and catechol ligand. The stability test in aqueous media with Tween 80 demonstrated that although the complex may not be stable in an aqueous solution for more than a few hours, this stability is not changed significantly in the presence of Tween 80 used for the administration of the compound. Hence, the compound stability is sufficient for the complex to exerts its action. Therefore, these studies are very encouraging and demonstrate that a vanadium compound such as the $[\mathrm{VO}(\mathrm{HSHED}) \mathrm{dtb}]$ complex does not exert toxicity to the same degree as vanadate even in a complex with a ligand that has potential for toxicity.

Author Contributions: H.M., D.J.G., and D.C.C. carried out the chemical methodology. L.M.A.L., M.F.B., W.E.S., and E.C.L. performed the biological studies. M.F.B., W.E.S., E.C.L., H.M., and D.C.C. reviewed and edited the manuscript; L.M.A.L. wrote drafting preparation and carried out the biological studies. E.C.L. and D.C.C. supervised the project. All authors have read and agreed to the published version of the manuscript.

Funding: This research was funded by CAPES, CNPq, and FACEPE. D.C.C. thanks the Arthur P. Cope Foundation for partial funding.

Institutional Review Board Statement: The protocols for these experiments were approved by the Animal Ethics Committee of the Universidade Federal de Pernambuco (process number \#004-2019) and conducted in accordance with the Ethical Principles in Animal Research.

Informed Consent Statement: Not applicable. 
Acknowledgments: L.M.A.L would like to thank FACEPE for the scholarship (AMD 0060-1.06/2019) at Colorado State University-Colorado/EUA with D.C.C.

Conflicts of Interest: The authors declare no conflict of interest.

$\begin{array}{ll}\text { Abbreviations } \\ \text { ADME } & \text { Absorption, Distribution, Metabolism and Excretion } \\ \text { ALB } & \text { albumin } \\ \text { ALT } & \text { alanine aminotransferase } \\ \text { Alx } & \text { allixinate } \\ \text { ANOVA } & \text { one-way analysis of variance } \\ \text { AST } & \text { aspartate aminotransferase } \\ \text { BMOV } & \text { bis(maltolato)oxidovanadium(IV) } \\ \text { BUN } & \text { blood urea nitrogen } \\ \text { CRE } & \text { creatinine } \\ \text { Dipic } & \text { dipicolinate } \\ \text { Dtb } & \text { 3,5-di(t-butyl)catechol } \\ \text { EDTA } & \text { ethylenediamine tetraacetic acid } \\ \text { GHS } & \text { Globally Harmonized System } \\ \text { GLB } & \text { globulin } \\ \text { Hb } & \text { hemoglobin } \\ \text { HCT } & \text { hematocrit } \\ \text { HPLC } & \text { high performance liquid chromatography } \\ \text { i.p } & \text { intraperitoneal administration } \\ \text { LD50 } & \text { median lethal dose } \\ \text { LIKA } & \text { Laboratory of the immunopathology of Keizo Asami } \\ \text { L-Pheol-im } & \text { L-phenylalaninol } \\ \text { LYM } & \text { lymphocytes } \\ \text { MCH } & \text { mean corpuscular hemoglobin } \\ \text { MCHC } & \text { mean corpuscular hemoglobin concentration } \\ \text { NMR } & \text { nuclear magnetic ressonance } \\ \text { NOAEL } & \text { no-observed adverse-effect level } \\ \text { O.G } & \text { oral gavage } \\ \text { OECD } & \text { Organization for Economic Cooperation and Development } \\ \text { RBC } & \text { red blood cells } \\ \text { Rpm } & \text { rotation per minute } \\ \text { SD } & \text { standard deviation } \\ \text { STZ } & \text { streptozotocin } \\ \text { TP } & \text { total protein } \\ \text { UV-Vis } & \text { Ultraviolet-visible spectroscopy } \\ \text { WBC } & \text { white blood cells } \\ \text { 8HQ } & \text { hydroxyquinoline } \\ & \end{array}$

\section{References}

1. Correia, I.; Adao, P.; Roy, S.; Wahba, M.; Matos, C.; Maurya, M.R.; Marques, F.; Pavan, F.R.; Leite, C.Q.F.; Avecilla, F.; et al. Hydroxyquinoline Derived Vanadium (IV and V) and Copper (II) Complexes as Potential Anti-Tuberculosis and Anti-Tumor Agents. J. Inorg. Biochem. 2014, 141, 83-93.

2. Crans, D.C. Antidiabetic, Chemical, and Physical Properties of Organic Vanadates as Presumed Transition-State Inhibitors for Phosphatases. J. Org. Chem. 2015, 80, 11899-11915.

3. McLauchlan, C.C.; Peters, B.J.; Willsky, G.R.; Crans, D.C. Vanadium-Phosphatase Complexes: Phosphatase Inhibitors Favor the Trigonal Bipyramidal Transition State Geometries. Coord. Chem. Rev. 2015, 301, 163-199.

4. Pessoa, J.C.; Etcheverry, S.; Gambino, D. Vanadium Compounds in Medicine. Coord. Chem. Rev. 2015, $301,24-48$.

5. Thompson, K.H.; Liboiron, B.D.; Sun, Y.; Bellman, K.D.; Setyawati, I.A.; Patrick, B.O.; Karunaratne, V.; Rawji, G.; Wheeler, J.; Sutton, K.; et al. Preparation and Characterization of Vanadyl Complexes with Bidentate Maltol-Type Ligands; in vivo Comparisons of Anti-Diabetic Therapeutic Potential. J. Biol. Inorg. Chem. 2003, 8, 66-74.

6. Wei, Y.B.; Yang, X.D. Synthesis, Characterization and Anti-Diabetic Therapeutic Potential of a New Benzyl Acid-Derivatized Kojic Acid Vanadyl Complex. BioMetals 2012, 25, 1261-1268. 
7. Kioseoglou, E.; Petanidis, S.; Gabriel, C.; Salifoglou, A. The Chemistry and Biology of Vanadium Compounds in Cancer Therapeutics. Coord. Chem. Rev. 2015, 301, 87-105.

8. Heyliger, C.E.; Tahiliani, A.G.; McNeill, J.H. Effect of Vanadate on Elevated Glucose and Depressed Cardiac Performance of Diabetic Rats. Science 1985, 227, 1474-1477.

9. Thompson, K.H.; Orvig, C. Vanadium in Diabetes: 100 Years from Phase 0 to Phase I. J. Inorg. Biochem. 2006, $100,1925-1935$.

10. Crans, D.C.; Henry, L.R.; Cardiff, G.; Posner, B.I. Developing Vanadium as an Antidiabetic or Anticancer Drug: A Clinical and Historical Perspective. Met. Ions Life Sci. 2019, 19, 203-230.

11. Willsky, G.R.; Goldfine, A.B.; Kostyniak, P.J.; McNeill, J.H.; Yang, L.Q.; Khan, H.R.; Crans, D.C. Effect of Vanadium (IV) Compounds in the Treatment of Diabetes: In vivo and in vitro Studies with Vanadyl Sulfate and Bis(Maltolato)Oxovandium(IV). J. Inorg. Biochem. 2001, 85, 33-42.

12. Mjos, K.D.; Orvig, C. Metallodrugs in Medicinal Inorganic Chemistry. Chem. Rev. 2014, 114, 4540-4563.

13. Tolman, E.L.; Barris, E.; Burns, M.; Pansini, A.; Partridge, R. Effects of Vanadium on Glucose Metabolism in vitro. Life Sci. 1979, 25, 1159-1164.

14. Crans, D.C.; Gambino, D.; Etcheverry, S.B. Vanadium Science: Chemistry, Catalysis, Materials, Biological and Medicinal Studies. New J. Chem. 2019, 43, 17535-17537.

15. Ramanadham, S.; Mongold, J.J.; Brownsey, R.W.; Cros, G.H.; McNeill, J.H. Oral Vanadyl Sulfate in Treatment of Diabetes Mellitus in Rats. Am. J. Physiol. Circ. Physiol. 1989, 257, 904-911.

16. Cam, M.C.; Pederson, R.A.; Brownsey, R.W.; McNeill, J.H. Long-Term Effectiveness of Oral Vanadyl Sulphate in StreptozotocinDiabetic Rats. Diabetologia 1993, 36, 218-224.

17. León, I.E.; Cadavid-Vargas, J.F.; Tiscornia, I.; Porro, V.; Castelli, S.; Katkar, P.; Desideri, A.; Bollati-Fogolin, M.; Etcheverry, S.B. Oxidovanadium(IV) Complexes with Chrysin and Silibinin: Anticancer Activity and Mechanisms of Action in a Human Colon Adenocarcinoma Model. J. Biol. Inorg. Chem. 2015, 20, 1175-1191.

18. Selman, M.; Rousso, C.; Bergeron, A.; Son, H.H.; Krishnan, R.; El-sayes, N.A.; Varette, O.; Chen, A.; Le Boeuf, F.; Tzelepis, F.; et al. Multi-Modal Potentiation of Oncolytic Virotherapy by Vanadium Compounds. Mol. Ther. 2018, 26, 56-69.

19. Levina, A.; Pires Vieira, A.; Wijetunga, A.; Kaur, R.; Koehn, J.T.; Crans, D.C.; Lay, P.A. A Short-Lived but Highly Cytotoxic Vanadium(V) Complex as a Potential Drug Lead for Brain Cancer Treatment by Intratumoral Injections. Angew. Chemie Int. Ed. 2020, 59, 15834-15838.

20. Hiromura, M.; Adachi, Y.; Machida, M.; Hattori, M.; Sakurai, H. Glucose Lowering Activity by Oral Administration of Bis (Allixinato)Oxidovanadium (Iv) Complex in Streptozotocin-Induced Diabetic Mice and Gene Expression Profiling in Their Skeletal Muscles. Metallomics 2009, 1, 92-100.

21. Thompson, K.H.; Lichter, J.; LeBel, C.; Scaife, M.C.; McNeill, J.H.; Orvig, C. Vanadium Treatment of Type 2 Diabetes: A View to the Future. J. Inorg. Biochem. 2009, 103, 554-558.

22. Crans, D.C. Chemistry and Insulin-like Properties of Vanadium (IV) and Vanadium (V) Compounds. J. Inorg. Biochem. 2000, 80, 123-131.

23. Boden, G.; Chen, X.; Ruiz, J.; Van Rossum, G.D.V.; Turco, S. Effects of Vanadyl Sulfate on Carbohydrate and Lipid Metabolism in Patients with Non-Insulin-Dependent Diabetes Mellitus. Metab. Clin. Exp. 1996, 45, 1130-1135.

24. Willsky, G.R.; Chi, L.H.; Godzala, M.; Kostyniak, P.J.; Smee, J.J.; Trujillo, A.M.; Alfano, J.A.; Ding, W.; Hu, Z.; Crans, D.C. Anti-Diabetic Effects of a Series of Vanadium Dipicolinate Complexes in Rats with Streptozotocin-Induced Diabetes. Coord. Chem. Rev. 2011, 255, 2258-2269.

25. Koyuturk, M.; Tunali, S.; Bolkent, S.; Yanardag, R. Effects of Vanadyl Sulfate on Liver of Streptozotocin-Induced Diabetic Rats. Biol. Trace Elem. Res. 2005, 104, 233-247.

26. Sakurai, H.; Tsuchiya, K.; Nukatsuka, M.; Kawada, J.; Ishikawa, S.; Yoshida, H.; Komatsu, M. Insulin-Mimetic Action of Vanadyl Complexes. J. Clin. Biochem. Nutr. 1990, 8, 193-200.

27. Crans, D.; Trujillo, A.; Pharazyn, P.; Cohen, M. How Environment Affects Drug Activity: Localization, Compartmentalization and Reactions of a Vanadium Insulin-Enhancing Compound, Dipicolinatooxovanadium(V). Coord. Chem. Rev. 2011, 255, $2178-2192$.

28. Bergeron, A.; Kostenkova, K.; Selman, M.; Murakami, H.; Owens, E.; Haribabu, N.; Arulanandam, R.; Diallo, J.S.; Crans, D. Enhancement of Oncolytic Virotherapy by Vanadium(V) Dipicolinates. BioMetals 2019, 32, 545-561.

29. Chinedu, E.; David, A.; Fidelis, S. A New Method for Determining Acute Toxicity in Animal Models. Toxicol. Int. 2013, 20, 224-226.

30. Erhirhie, E.O.; Ihekwereme, C.P.; Ilodigwe, E.E. Advances in Acute Toxicity Testing: Strengths, Weaknesses and Regulatory Acceptance. Interdiscip. Toxicol. 2018, 11, 5-12.

31. Alhaji Saganuwan, S. Toxicity Studies of Drugs and Chemicals in Animals: An Overview. Bulg. J. Vet. Med. 2017, $20,291-318$.

32. Llobet, J.M.; Domingo, J.L. Acute Toxicity of Vanadium Compounds in Rats and Mice. Toxicol. Lett. 1984, $23,227-231$.

33. Mongold, J.J.; Cros, G.H.; Vian, L.; Tep, A.; Ramanadham, S.; Siou, G.; Diaz, J.; McNeill, J.H.; Serrano, J.J. Toxicological Aspects of Vanadyl Sulphate on Diabetic Rats: Effects on Vanadium Levels and Pancreatic B-Cell Morphology. Pharmacol. Toxicol. 1990, 67, 192-198.

34. Domingo, J.L.; Gomez, M.; Sanchez, D.J.; Llobet, J.M.; Keen, C.L. Toxicology of Vanadium Compounds in Diabetic Rats: The Action of Chelating Agents on Vanadium Accumulation. Mol. Cell. Biochem. 1995, 153, 233-240. 
35. Doucette, K.A.; Hassell, K.N.; Crans, D.C. Selective Speciation Improves Efficacy and Lowers Toxicity of Platinum Anticancer and Vanadium Antidiabetic Drugs. J. Inorg. Biochem. 2016, 165, 56-70.

36. Naso, L.; Ferrer, E.G.; Lezama, L.; Rojo, T.; Etcheverry, S.B.; Williams, P. Role of Oxidative Stress in the Antitumoral Action of a New Vanadyl(IV) Complex with the Flavonoid Chrysin in Two Osteoblast Cell Lines: Relationship with the Radical Scavenger Activity. J. Biol. Inorg. Chem. 2010, 15, 889-902.

37. Treviño, S.; Díaz, A.; Sánchez-Lara, E.; Sanchez-Gaytan, B.L.; Perez-Aguilar, J.M.; González-Vergara, E. Vanadium in Biological Action: Chemical, Pharmacological Aspects, and Metabolic Implications in Diabetes Mellitus. Biol. Trace Elem. Res. 2019, 188, 68-98.

38. Yilmaz-Ozden, T.; Kurt-Sirin, O.; Tunali, S.; Akev, N.; Can, A.; Yanardag, R. Ameliorative Effect of Vanadium on Oxidative Stress in Stomach Tissue of Diabetic Rats. Bosn. J. Basic Med. Sci. 2014, 14, 105-109.

39. Cortizo, A.M.; Bruzzone, L.; Molinuevo, S.; Etcheverry, S.B. A Possible Role of Oxidative Stress in the Vanadium-Induced Cytotoxicity in the MC3T3E1 Osteoblast and UMR106 Osteosarcoma Cell Lines. Toxicology 2000, 147, 89-99.

40. Kowalski, S.; Wyrzykowski, D.; Inkielewicz-Stepniak, I. Molecular and Cellular Mechanisms of Cytotoxic Activity of Vanadium Compounds against Cancer Cells. Molecules 2020, 25, 1757.

41. Rojas-Lemus, M.; Patricia, B.N.; Nelly, L.V.; Gonzalez-Villalva, A.; Gabriela, G.P.; Eugenia, C.V.; Otto, T.C.; Norma, R.F.; Brenda, C.T.; Martha, U.C.; et al. Oxidative Stress and Vanadium. In Antimutagens-Mechanisms of DNA Protection; Intech Open: London, UK, 2020.

42. Irving, E.; Stoker, A.W. Vanadium Compounds as PTP Inhibitors. Molecules 2017, 22, 2269.

43. Saibu, M.; Sagar, S.; Green, I.; Ameer, F.; Meyer, M. Evaluating the Cytotoxic Effects of Novel Quinone Compounds. Anticancer Res. 2014, 34, 4077-4086.

44. Sanna, D.; Ugone, V.; Fadda, A.; Micera, G.; Garribba, E. Behavior of the Potential Antitumor VIVO Complexes Formed by Flavonoid Ligands. 3. Antioxidant Properties and Radical Production Capability. J. Inorg. Biochem. 2016, 161, 18-26.

45. Dankhoff, K.; Ahmad, A.; Weber, B.; Biersack, B.; Schobert, R. Anticancer Properties of a New Non-Oxido Vanadium (IV) Complex with a Catechol-Modified 3,3'-Diindolylmethane Ligand. J. Inorg. Biochem. 2019, 194, 1-6.

46. Li, M.; Wei, D.; Ding, W.; Baruah, B.; Crans, D.C. Anti-Diabetic Effects of Cesium Aqua (N,N'-Ethylene(Salicylideneiminato)-5Sulfonato) Oxovanadium (IV) Dihydrate in Streptozotocin-Induced Diabetic Rats. Biol. Trace Elem. Res. 2008, 121, $226-232$.

47. Crans, D.C.; Mahroof-Tahir, M.; Johnson, M.D.; Wilkins, P.C.; Yang, L.; Robbins, K.; Johnson, A.; Alfano, J.A.; Godzala, M.E.; Austin, L.T.; et al. Vanadium (IV) and Vanadium (V) Complexes of Dipicolinic Acid and Derivatives. Synthesis, X-Ray Structure, Solution State Properties and Effects in Rats with STZ-Induced Diabetes. Inorg. Chim. Acta 2003, 356, 365-378.

48. Tadele, K.T.; Tsega, T.W. Schiff Bases and Their Metal Complexes as Potential Anticancer Candidates: A Review of Recent Works. Anti Cancer Agents Med. Chem. 2019, 19, 1786-1795.

49. Kowalski, S.; Wyrzykowski, D.; Hac, S.; Rychlowski, M.; Radomski, M.W.; Inkielewicz-Stepniak, I. New Oxidovanadium(IV) Coordination Complex Containing 2-Methylnitrilotriacetate Ligands Induces Cell Cycle Arrest and Autophagy in Human Pancreatic Ductal Adenocarcinoma Cell Lines. Int. J. Mol. Sci. 2019, 20, 261.

50. Lewis, N.A.; Liu, F.; Seymour, L.; Magnusen, A.; Erves, T.R.; Arca, J.F.; Beckford, F.A.; Venkatraman, R.; González-Sarrías, A.; Fronczek, F.R.; et al. Synthesis, Characterization, and Preliminary in vitro Studies of Vanadium(IV) Complexes with a Schiff Base and Thiosemicarbazones as Mixed-Ligands. Eur. J. Inorg. Chem. 2012, 2012, 664-677.

51. Leon, I.E.; Cadavid-Vargas, J.F.; Di Virgilio, A.L.; Etcheverry, S.B. Vanadium, Ruthenium and Copper Compounds: A New Class of Nonplatinum Metallodrugs with Anticancer Activity. Curr. Med. Chem. 2017, 24, 112-148.

52. Leon, I.E.; Díez, P.; Etcheverry, S.; Fuentes, M. Deciphering the Effect of an Oxovanadium(IV) Complex with the Flavonoid Chrysin (VOChrys) in Intracellular Cell Signalling Pathways in an Osteosarcoma Cell Line. Metallomics 2016, 8, 739-749.

53. León, I.E.; Butenko, N.; Di Virgilio, A.L.; Muglia, C.I.; Baran, E.J.; Cavaco, I.; Etcheverry, S.B. Vanadium and Cancer Treatment: Antitumoral Mechanisms of Three Oxidovanadium(IV) Complexes on a Human Osteosarcoma Cell Line. J. Inorg. Biochem. 2014, 134, 106-117.

54. Nica, S.; Rudolph, M.; Lippold, I.; Buchholz, A.; Görls, H.; Plass, W. Vanadium(V) Complex with Schiff-Base Ligand Containing a Flexible Amino Side Chain: Synthesis, Structure and Reactivity. J. Inorg. Biochem. 2015, 147, 193-203.

55. Cornman, C.R.; Colpas, G.J.; Hoeschele, J.D.; Kampf, J.; Pecoraro, V.L. Implications for the Spectroscopic Assignment of Vanadium Biomolecules: Structural and Spectroscopic Characterization of Monooxovanadium(V) Complexes Containing Catecholate and Hydroximate Based Noninnocent Ligands. J. Am. Chem. Soc. 1992, 114, 9925-9933.

56. Crans, D.C.; Koehn, J.T.; Petry, S.M.; Glover, C.M.; Wijetunga, A.; Kaur, R.; Levina, A.; Lay, P.A. Hydrophobicity May Enhance Membrane Affinity and Anti-Cancer Effects of Schiff Base Vanadium(v) Catecholate Complexes. Dalt. Trans. 2019, 48, 6383-6395.

57. Boukhobza, I.; Crans, D.C. Application of HPLC to Measure Vanadium in Environmental, Biological and Clinical Matrices. Arabian J. Chem. 2020, 13, 1198-1228.

58. Ugone, V.; Sanna, D.; Sciortino, G.; Crans, D.C.; Garibba, E. ESI-MS Study of the Interaction of Potential VIV Drugs. Inorg. Chem. 2020, 59, 9739-9755.

59. Srivastava, A. Anti-Diabetic and Toxic Effects of Vanadium Compounds. Mol. Cell. Biochem. 2000, 206, 177-182.

60. OECD. Test No. 423: Acute Oral Toxicity—Acute Toxic Class Method; OECD Guidelines for the Testing of Chemicals, Section 4; OECD Publishing: Paris, France, 2002. 
61. Lipnick, R.L.; Cotruvo, J.A.; Hill, R.N.; Bruce, R.D.; Stitzel, K.A.; Walker, A.P.; Chu, I.; Goddard, M.; Segal, L.; Springer, J.A.; et al. Comparison of the Up-and-down, Conventional LD50, and Fixed-Dose Acute Toxicity Procedures. Food Chem. Toxicol. 1995, 33, 223-231.

62. Ozer, J.; Ratner, M.; Shaw, M.; Bailey, W.; Schomaker, S. The Current State of Serum Biomarkers of Hepatotoxicity. Toxicology 2008, 245, 194-205.

63. McGill, M.R. The Past and Present of Serum Aminotransferases and the Future of Liver Injury Biomarkers. EXCLI J. 2016, 15, 817-828.

64. Pan, X.; Chang, F.; Liu, Y.; Li, D.; Xu, A.; Shen, Y.; Huang, Z. Mouse Toxicity of Anabaena Flos-Aquae from Lake Dianchi, China. Environ. Toxicol. 2009, 24, 10-18.

65. Edelstein, C.L. Biomarkers of Acute Kidney Injury. Adv. Chronic Kidney Dis. 2008, 15, 222-234.

66. Cooper, R.G. Vanadium Pentoxide Inhalation. Indian J. Occup. Environ. Med. 2007, 11, 97-102.

67. Crans, D.C.; Postal, K.; MacGregor, J.A. Vanadium-speciation Chemistry is Important when Assessing Health Effects on Living Systems. In Metal Toxicology Handbook; CRC Press: Boca Raton, FL, USA, 2020; Chapter 6.

68. Gajens, J.; Meier, B.; Adachi, Y.; Sakurai, H.; Rehder, D. Characterization and Insulin-Mimetic Potential of Oxidovanadium (IV) Complexes Derived from Monoesters and -carboxylates of 2,5-Dipicolinic Acid. Eur. J. Inorg. Chem. 2006, 18, 3575-3585.

69. Brichard, S.M.; Henquin, J.C. The Role of Vanadium in the Management of Diabetes. Trends Pharmacol. Sci. 1995, 16, 265-270.

70. Hanson, G.R.; Sun, Y.; Orvig, C. Characterization of the Potent Insulin Mimetic Agent Bis (Maltolato) Oxovanadium (IV) (BMOV) in Solution by EPR Spectroscopy. Inorg. Chem. 1996, 35, 6507-6512.

71. Pessoa, J.C.; Correa, I. Misinterpretations in Evaluating Interactions of Vanadium Complexes with Proteins and Other Biological Targets. Inorganics 2021, 9, 17.

72. Wang, B.; Tanaka, K.; Morita, A.; Ninomiya, Y.; Maruyama, K.; Fujita, K.; Hosoi, Y.; Nenoi, M. Sodium Orthovanadate (Vanadate), a Potent Mitigator of Radiation-Induced Damage to the Hematopoietic System in Mice. J. Radiat. Res. 2013, 54, 620-629.

73. Roy, S.; Majumdar, S.; Singh, A.K.; Ghosh, B.; Ghosh, N.; Manna, S.; Chakraborty, T.; Mallick, S. Synthesis, Characterization, Antioxidant Status, and Toxicity Study of Vanadium-Rutin Complex in Balb/c Mice. Biol. Trace Elem. Res. 2015, 166, 183-200.

74. Sanchez, D.; Ortega, A.; Domingo, J.L.; Corbella, J. Developmental Toxicity Evaluation of Orthovanadate in the Mouse. Biol. Trace Elem. Res. 1991, 30, 219-226.

75. Montaser, A.S.; Wassel, A.R.; Al-Shaye'a, O.N. Synthesis, characterization and antimicrobial activity of Schiff bases from chitosan and salicylaldehyde $/ \mathrm{TiO}_{2}$ nanocomposite membrane. Int. J. Biol. Macromol. 2019, 124, 802-809.

76. Kenkyūjo, K.G.S. Toxic and Hazardous Industrial Chemicals Safety Manual or Handling and Disposal with Toxicity and Hazard Data; The International Technical Information Institute: Tokyo, Japan, 1988; p. 591.

77. Miadzvedski, I.; Nikolayuk, O.; Dubovik, B. Acute Toxicity of Spatially Hindered Derivatives of Aminophenol and Catechol. In Proceedings of the Actual Problems of Medicine, Grodno, Belarus, January 2013.

78. Boehm, O.; Zur, B.; Koch, A.; Tran, N.; Freyenhagen, R.; Hartmann, M.; Zacharowski, K. Clinical Chemistry Reference Database for Wistar Rats and C57/BL6 Mice. Biol Chem. 2007, 388, 547-554.

79. Reul, B.A.; Amin, S.S.; Buchet, J.; Ongemba, L.N.; Crans, D.C.; Brichard, S.M. Effects of Vanadium Complexes with Organic Ligands on Glucose Metabolism: A Comparison Study in Diabetic Rats. Br. J. Pharmacol. 1999, 126, 467-477.

80. Levina, A.; Crans, D.C.; Lay, P.A. Speciation of Metal Drugs, Supplements and Toxins in Media and Bodily Fluids Controls in vitro Activities. Coor. Chem. Rev. 2017, 352, 473-498.

81. Elvingson, K.; Gonzalez Baro, A.; Pettersson, L. Speciation in Vanadium Bioinorganic Systems. 2. An NMR, ESR, and Potentiometric Study of the Aqueous H+-Vanadate-Maltol System. Inorg. Chem. 1996, 35, 3388-3393.

82. Samart, N.; Arhouma, Z.; Kumar, S.; Murakami, H.A. Decavanadate Inhibits Mycobacterial Growth More Potently Than Other Oxovanadates. Front. Chem. 2018, 6, 1-16.

83. Althumairy, D.; Postal, K.; Barisas, G.B.; Nunes, G.G.; Roess, D.A.; Crans, D.C. Polyoxometalates Function as Indirect Activators of a G Protein-Coupled Receptor. Metallomics 2020, 12, 1044-1061.

84. Yoshikawa, Y.; Sakurai, H.; Crans, D.C.; Micera, G.; Garribba, E. Structural and Redox Requirements for the Action of Anti-Diabetic Vanadium Compounds. Dalt. Trans. 2014, 43, 6965-6972.

85. Ścibior, A.; Pietrzyk, Ł.; Plewa, Z.; Skiba, A. Vanadium: Risks and Possible Benefits in the Light of a Comprehensive Overview of Its Pharmacotoxicological Mechanisms and Multi-Applications with a Summary of Further Research Trends. J. Trace Elem. Med. Biol. 2020, 61, 126508.

86. Lima, L.M.A.; Belian, M.F.; Silva, W.E.; Postal, K.; Kostenkova, K.; Crans, D.C.; Rossiter, A.K.F.F.; da Silva Júnior, V.A. Vanadium (IV)-Diamine Complex with Hypoglycemic Activity and a Reduction in Testicular Atrophy. J. Inorg. Biochem. 2020, $216,111312$.

87. Crans, D.C.; Shin, P.K.; Armstrong, K.B. Characterization of vanadium(V) complexes in aqueous solutions: Ethanolamine and glycine derived complexes. J. Am. Chem. Soc. 1994, 116, 1305-1315.

88. Rehder, D.; Polenova, T.; Bühl, M. Vanadium-51 NMR. Annu. Rep. NMR Spectrosc. 2007, 62, 49-114.

89. Li, X.; Lah, M.S.; Pecoraro, V.L. Vanadium Complexes of the Tridentate Schiff Base Ligand N-Salicylidene-N'-(2-Hydroxyethyl) Ethylenediamine: Acid-Base and Redox Conversion between Vanadium (IV) and Vanadium (V) Imino Phenolates. Inorg. Chem. 1988, 27, 4657-4664. 
90. Rajendiran, V.; Karthik, R.; Palaniandavar, M.; Stoeckli-Evans, H.; Periasamy, V.S.; Akbarsha, M.A.; Srinag, B.S.; Krishnamurthy, H. Mixed-ligand Copper (II)-phenolate Complexes: Effect of Coligand on Enhanced DNA and Protein Binding, DNA Cleavage, and Anticancer Activity K. Inorg. Chem. 2007, 46, 8208-8221.

91. Chatterjee, P.B.; Goncharov-Zapata, O.; Quinn, L.L.; Hou, G.; Hamaed, H.; Schurko, R.W.; Polenova, T.; Crans, D.C. Characterization of Non-innocent Metal Complexes Using Solid-state NMR Spectroscopy: O-dioxolene Vanadium Complexes. Inorg. Chem. 2011, 50, 9794-9803.

92. Hasegawa, R.; Nakaji, Y.; Kurokawa, Y.; Tobe, M. Acute Toxicity Tests on 113 Environmental Chemicals. Sci. Rep. Res. Inst. Tohoku Univ. Med. 1989, 36, 10-16.

93. Barbosa, H.M.; Do Nascimento, J.N.; Araújo, T.A.S.; Duarte, F.S.; Albuquerque, U.P.; Vieira, J.R.C.; De Santana, E.R.B.; Yara, R.; Lima, C.S.A.; Gomes, D.A.; et al. Acute Toxicity and Cytotoxicity Effect of Ethanolic Extract of Spondias Tuberose Arruda Bark: Hematological, Biochemical and Histopathological Evaluation. An. Acad. Bras. Cienc. 2016, 88, 1993-2004.

94. Howard, W.; Robinson, J.W.P.; Hogden, C.G. The Estimation of Albumin and Globulin in Blood. J. Bio. Chem. 1937, 120, 481-498. 